\title{
Epidemiological and socioeconomic profile of cerebral palsy from the aspect of mothers in giresun, Turkey
}

\begin{abstract}
Cerebral Palsy is considered a neurological disorder caused by a non-progressive brain injury or malformation that occurs while the child's brain is under development. Cerebral Palsy primarily affects body movement and muscle coordination. It can also impact fine motor skills, gross motor skills, and oral motor functioning. Balance, posture, and coordination can also be affected by Cerebral Palsy. Tasks such as walking, sitting, or tying shoes may be difficult for some, while others might have difficulty grasping objects. In this study, we conducted a survey to investigate the cerebral palsy in Giresun, Turkey. We tried to get statistical clues to understanding the disease.
\end{abstract}

Keywords: cerebral palsy, quality of life, education
Volume 3 Issue 5 - 2018

\author{
Esin Avci,' Ilker Ilhanli, ${ }^{2}$ Canan Celik, ${ }^{2}$ Aslı \\ Kurt Genc,' Esra Kozleme' \\ 'Department of Statistics, Faculty of Science, Giresun University, \\ Turkey \\ ${ }^{2}$ Department of Physical Medicine and Rehabilitation, Giresun \\ University, Turkey
}

Correspondence: Ilker Ilhanli, MD, Assoc. Prof, Department of Physical Medicine and Rehabilitation, School of Medicine, Giresun University, 28200, Giresun, Turkey, Tel +904543 I01600, Email ilkarilhanli@hotmail.com

Received: October 02, 2018 | Published: October 10, 2018

\section{Introduction}

Cerebral Palsy (CP) is considered a neurological disorder caused by a non-progressive brain injury or malformation that occurs while the child's brain is under development. ${ }^{1} \mathrm{CP}$ primarily affects body movement and muscle coordination. $\mathrm{CP}$ is actually caused by brain damage. The brain damage is caused by brain injury or abnormal development of the brain that occurs while a child's brain is still developing -before birth, during birth, or immediately after birth. CP affects body movement, muscle control, muscle coordination, muscle tone, reflex, posture, and balance. It can also impact fine motor skills, gross motor skills and oral motor functioning. ${ }^{2}$

Other complications, such as intellectual impairment, seizures, and vision or hearing impairment also commonly accompany $\mathrm{CP} .{ }^{3} \mathrm{CP}$ is seen at 2 every 1000 live births. ${ }^{4}$ Prevalence of CP is 2-4.4 /1000 live births in Turkey. ${ }^{5,6}$

Based upon the form of motor impairment, $\mathrm{CP}$ can be divided into types: ${ }^{7}$

i. Spastic (unilateral or bilateral) CP,

ii. Non-spastic

a) Dyskinetic CP (according to the predominant symptoms dyskinetic CP may be either dystonic or choreoathetotic).

b) Ataxic CP.

iii. Mixed type.

These categories are not rigid, and the majority of patients most probably have a mixture of them.

There are little epidemiologic studies from CP centers in our country. ${ }^{8-11}$ We aimed to support the general data of CP patients in our country by investigating the $\mathrm{CP}$ patients from the aspect of mothers in our city.

\section{Materials and methods}

This SAG-BAP-A-140316-91 numbered study was supported by Giresun University Scientific Research and Projects Unit and approved by the Giresun University Clinical Researches Ethics Committee. Permission from the Provincial Directorate of National Education was taken for 5 private and 1 state institutions. The survey was conducted between December 2017 and February 2018. A hundred mothers $(\mathrm{N}=100)$ participated. Age of $\mathrm{CP}$ patients was 2-54 (Median=28 years). A survey questionnaire was used as the data collection tool in the research.

i. The questionnaire consists of 4 parts:

ii. Socio-demographic information (12 questions)

iii. Information on the health of the individual with $\mathrm{CP}$ (18 questions)

iv. Information on mother's health (11 questions)

v. The quality of life (SF36) form (36 questions)

\section{Statistical analysis}

Respectively, mean \pm standard deviation and median (Min-Max) reported for variables that normal and non-normal assumed. MannWhitney U and Independent Samples t-Test were conducted to explore the relationship between females and males, and sub-groups of SF36. Moreover, the Kruskal-Wallis test and One Way ANOVA were used for comparison between sub-groups of SF-36 and cerebral palsy type. Multiple comparison tests were applied to examine statistically different groups (Mann-Whitney U and Tukey). To display the change of prevalence according to age, group and year, line plot was used. SPSS 17 software was used for data analysis. 


\section{Results}

\section{Socio-demographic findings}

A questionnaire consisting of 12 questions was used as the data collection tool in the research. Mean age of the CP patients was $24.52 \pm 15.75$. $66 \%$ of the individuals with $\mathrm{CP}$ living in Giresun and participated in this study were female and $34 \%$ were male.

Males with CP mostly were living in towns and cities $(6 \%$ and $72 \%$ ). $29 \%$ of females were living in villages ( $6 \%$ in towns and $72 \%$ in cities) while $22 \%$ of males were living in villages.

It has been determined that the majority of the individuals with CP living in Giresun (80\%) weren't literate (3\% high school, 5\% primary school, and $12 \%$ literate). Female individuals with $\mathrm{CP}$ were found to be more educated (23\%). The majority $(85 \%)$ of the males weren't literate. Mothers of non-literate individuals were found to have high school and university graduates (94\% and $89 \%)$. Fathers of non-literate individuals were found to have high school and university graduates (100\% and $100 \%)$.

Any of the participants with $\mathrm{CP}$ was working. All mothers of nonliterate individuals were working in the private sector or they were self-employed. It was determined that the rate of working mothers of individuals with $\mathrm{CP}$ who were graduated from primary and high school was so low $(6 \%$ and $4 \%)$. Most of the fathers of non-literate individuals were working in the private sector or they were selfemployed ( $81 \%$ and $91 \%)$. It was determined that most of the fathers of individuals with $\mathrm{CP}$ who were graduated from primary and high school were working as a public servant $(20 \%$ and $10 \%)$.

All mothers of the participants were alive. It has been determined that the father of $5 \%$ wasn't alive. $95 \%$ of the couples were found to be married and living in the same house.

$56 \%$ of the individuals with $\mathrm{CP}$ had a family income between 1405-3000 TL (Turkish Liras, 1TL= 4.85 USD).

Most parents of the individuals with CP were not related (66\%). $53 \%$ of the relatives were found to have second-degree relation.

\section{Health of individuals with $C P$}

Table 1 summarizes the data of birth time, weight, and height, sitting, walking and speaking time of the patients. They had an average birth time of 35 weeks, birth weight of $2.5 \mathrm{~kg}$, height of 48 $\mathrm{cm}$, head holding time of 9 months, sitting time of 20 months, walking time of 35 months and speech time of 24 months.

Table I Health of individuals with cerebral palsy

\begin{tabular}{ll}
\hline Measures & $\begin{array}{l}\text { Mean } \pm \text { standard } \\
\text { deviation }\end{array}$ \\
\hline Birth Time (weeks) & $34.70 \pm 3.17$ \\
Birth weight $(\mathrm{Kg})$ & $2.55 \pm 0.78$ \\
Birth height (cm) & $48.43 \pm 6.04$ \\
Head Holding Time (months) & $8.90 \pm 14.35$ \\
Sitting Time (months) & $20.21 \pm 33.18$ \\
Walking Time (months) & $35.26 \pm 50.09$ \\
Speech Time (months) & $24.28 \pm 21.46$ \\
\hline
\end{tabular}

Table 2 shows the perinatal and postnatal data of the participants. The frequency of prematurity was found to be $79 \%$. The majority of them had postpartum fever (39\%). The most common CP type was Spastic Bilateral (Whole Body) (44\%). They were born in a hospital (94\%), by cesarean section (55\%), cried immediately after birth $(53 \%)$ and $81 \%$ had brother.

Table 2 Perinatal and postnatal data of the participants

\begin{tabular}{lll}
\hline & Status & $\%$ \\
\hline & Postpartum fever & 38.9 \\
Postpartum Diseases & Trauma & 27.8 \\
& Long-term jaundice & 13.9 \\
& Accident & 8.3 \\
Birth place & Home & 11.1 \\
Birth Type & Hospital & 6 \\
& Transvaginal & 94 \\
& Caesarean & 44 \\
& Interventions & 55 \\
& Spastic Bilateral & 1 \\
\hline & Dystonic-Ataxic & 8.2 \\
& Hemiplegic & 28.6 \\
& Mixed & 19.4 \\
\hline
\end{tabular}

Caregivers indicated that individuals had the most problems with hand skills and reading / writing (72\%), and that most of them didn't have problems getting commands (75\%). 39\% had epileptic seizures and 38\% had nutritional problems (Table 3).

Table 3 Observations of caregivers about co-morbid pathologies

\begin{tabular}{ll}
\hline Status & Yes (\%) \\
\hline Nutritional problems (swallowing etc.) & 38 \\
Command Takes (Do you understand what is said?) & 75 \\
Epileptic Seizure & 39.4 \\
Vision problems & 33 \\
Hearing Problems & 6 \\
Problem with hand skills & 71.7 \\
Speech problem & 72.1 \\
\hline
\end{tabular}

\section{Health of the mothers}

The health information of the mothers participating in the survey is summarized in Table 4. The average age of the mothers was 27 and the weight was $72 \mathrm{~kg}$ at the birth time. The most prevalent problem was tension in pregnancy (77\%). The most common chronic illnesses were hypertension and diabetes mellitus ( $72 \%$ and $39 \%$, respectively).

Most frequent caregiver of the individuals with $\mathrm{CP}$ was the mother (88\%); the least caregiver was the grandmother $(2 \%)$. Most of the caregivers don't get psychological support (88\%). Caregivers who get psychological support were taking medication (67\%), psychological therapy $(25 \%)$ and therapy + medication $(8 \%)$, respectively. 
Table 4 Health information of the mothers

\begin{tabular}{ll}
\hline & Mean \pm standard deviation \\
\hline Age at birth (years) & $27.31 \pm 4.75$ \\
Weight at birth $(\mathrm{Kg})$ & $71.5 \pm 11.34$ \\
\hline Status & Yes (\%) \\
\hline Eclampsia & 77 \\
Chronic Hypertension & 72 \\
Diabetes mellitus & 39
\end{tabular}

\section{Quality of life}

Short Form 36 (SF 36) was used. When the reliability was analyzed, the Cronbach Alpha coefficient of the questionnaire was 0.73 . It shows that the scale was pretty reliable. The sub-parameters of the questionnaire were given in Table 5.

Females had better social functionality score while males had better energy score. It was also found that females had higher scores than men in terms of physical function and physical role function. Males' mental health and general health perception were found to be higher than females.

Table 5 SF 36 sub parameter values according to gender

\begin{tabular}{|c|c|c|c|c|}
\hline Sub parameter & Female median (Min-Max) & Male median (Min-Max) & Z & $\mathrm{P}$ \\
\hline Physical Function & $65(0-100)$ & $57.5(0-100)$ & -0.449 & 0.654 \\
\hline Physical Role Function & $50(0-100)$ & $25(0-100)$ & -0.859 & 0.390 \\
\hline Emotional Role Function & $66.67(0-100)$ & $0(0-100)$ & -1.744 & $0.08 \mathrm{I}$ \\
\hline Energy / viability / vitality & $30(0-100)$ & $45(15-90)$ & -2.716 & $0.007^{*}$ \\
\hline Social Functionality & $75(0-100)$ & $43.75(0-100)$ & -2.173 & $0.030 *$ \\
\hline Pain & $66.25(0-100)$ & $77.5(22.5-100)$ & -0.488 & 0.626 \\
\hline Sub parameter & Female (mean \pm standard deviation) & Male (mean \pm standard deviation) & T Test & $\mathbf{p}$ \\
\hline Mental Health & $59.74 \pm 17.32$ & $62.71 \pm 16.96$ & -0.987 & 0.326 \\
\hline General Health Perception & $46.69 \pm 19.94$ & $54.56 \pm 21.19$ & -1.828 & $0.07 \mathrm{I}$ \\
\hline
\end{tabular}

*\%5 level of significance.

SF 36 sub-parameters according to CP type were given in Table 6 . There were significant differences between groups according to the physical function, physical role function, social functionality, pain and general health perception. According to the physical function, there were significant differences between Spastic Bilateral and Hemiplegic $(\mathrm{p}=0.000)$, Dystonic-Ataxic and Hemiplegic $(\mathrm{p}=0.008)$, and Hemiplegic and Unclassifiable type $(\mathrm{p}=0.043)$. According to the physical role function, there was a significant difference between
Spastic Bilateral and Hemiplegic type $(\mathrm{p}=0.003)$. According to the social functionality, there were significant differences between Spastic Bilateral and Hemiplegic $(\mathrm{p}=0.006)$, and Hemiplegic and Unclassifiable type $(\mathrm{p}=0.011)$. According to the pain, there was a significant difference between Spastic Bilateral and Hemiplegic $(p=0.003)$. According to the general health perception, there was a significant difference between Spastic Bilateral and Hemiplegic $(\mathrm{p}=0.009)$.

Table 6 SF 36 sub parameter values according to cerebral palsy type

\begin{tabular}{|c|c|c|c|c|c|c|}
\hline Sub-parameter & $\begin{array}{l}\text { Spastic bilateral median } \\
\text { (Min-Max) }\end{array}$ & $\begin{array}{l}\text { Dystonic-ataxic } \\
\text { median (Min-Max) }\end{array}$ & $\begin{array}{l}\text { Hemiplegic median } \\
\text { (Min-Max) }\end{array}$ & $\begin{array}{l}\text { Unclassifiable } \\
\text { median (Min-Max) }\end{array}$ & Kruskall-wallis Test $(\mathrm{H})$ & $\mathrm{p}$-value \\
\hline Physical Function & $20(0-100)$ & $57.5(0-80)$ & $80(5-100)$ & $52.5(0-100)$ & 17.536 & $0.001 *$ \\
\hline $\begin{array}{l}\text { Physical Role } \\
\text { Function }\end{array}$ & $0(0-100)$ & $50(0-100)$ & $62.5(0-100)$ & $50(0-100)$ & 9.765 & $0.02 I^{*}$ \\
\hline $\begin{array}{l}\text { Emotional Role } \\
\text { Function }\end{array}$ & $0(0-100)$ & $66.67(0-100)$ & $33.33(0-100)$ & $50(0-100)$ & 3.578 & 0.311 \\
\hline $\begin{array}{l}\text { Energy / viability / } \\
\text { vitality }\end{array}$ & $42.5(0-100)$ & $20(10-60)$ & $42.5(0-90)$ & $32.5(10-70)$ & 4.555 & 0.207 \\
\hline $\begin{array}{l}\text { Social } \\
\text { Functionality }\end{array}$ & $56.25(0-100)$ & $68.75(12.5-100)$ & $75(37.5-100)$ & $50(0-100)$ & 9.665 & $0.022^{*}$ \\
\hline Pain & $55(0-100)$ & $77.5(32.5-90)$ & $77.5(0-100)$ & $66.25(20-100)$ & 9.455 & $0.024^{*}$ \\
\hline Sub-parameter & $\begin{array}{l}\text { Spastic bilateral } \\
\text { (mean } \pm \text { standard } \\
\text { deviation) }\end{array}$ & $\begin{array}{l}\text { Dystonic-ataxic } \\
\text { (mean } \pm \text { standard } \\
\text { deviation) }\end{array}$ & $\begin{array}{l}\text { Hemiplegic } \\
\text { (mean } \pm \text { stan- } \\
\text { dard deviation) }\end{array}$ & $\begin{array}{l}\text { Unclassifiable } \\
\text { (mean } \pm \text { stan- } \\
\text { dard deviation) }\end{array}$ & $\begin{array}{l}\text { One-way ANOVA } \\
\text { (F) }\end{array}$ & p-value \\
\hline Mental Health & $63 \pm 16.20$ & $55.5 \pm 23.85$ & $57.7 \mid \pm 17.84$ & $63.11 \pm 15.86$ & 0.666 & 0.575 \\
\hline $\begin{array}{l}\text { General Health } \\
\text { Perception }\end{array}$ & $43 . \mid 3 \pm 21.11$ & $46.88 \pm|7.3|$ & $58.75 \pm 17.03$ & $51.11 \pm 22.85$ & 3.552 & $0.017^{*}$ \\
\hline
\end{tabular}

*\%5 level of significance. 


\section{Prevalence}

Prevalence is calculated according to the data of 2017 Giresun population obtained from Turkish Statistical Institute Trabzon Regional Directorate. Over the past 10 years, the prevalence of $\mathrm{CP}$ has increased. Prevalence according to age and years is given in (Figure $1 \&$ Figure 2).

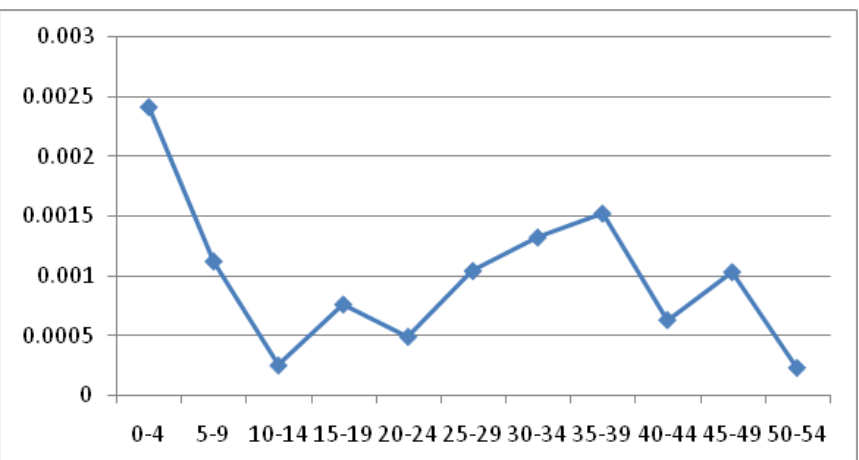

Figure I Prevalence of cerebral palsy according to the age intervals.

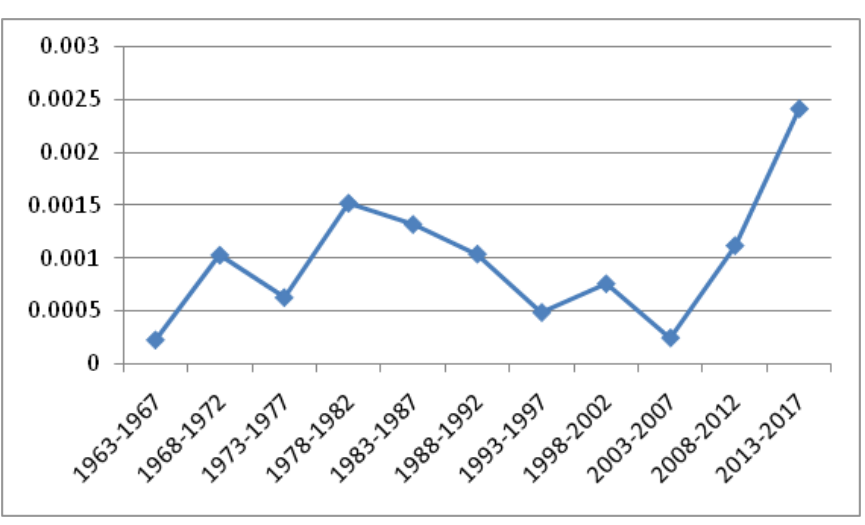

Figure 2 Prevalence of cerebral palsy according to the years.

Most common type in females was Spastic Bilateral (52\%) and in males was non-classified (32\%). There was no difference according to CP type.

It was found that females had more problems with eating (swallowing) than males. The most common types of $\mathrm{CP}$ in the home births were dystonic-ataxic and hemiplegic types (40\%) and in the hospital births were spastic bilateral (45\%). There was no difference according to the birthplace.

\section{Discussion}

Similar to some findings from Turkey ${ }^{8,9,12}$ and Europe, ${ }^{13}$ spastic bilateral was the most common type in our study. Similar to the literature a common risk factor for $\mathrm{CP}$ was prematurity. ${ }^{8}$ Consanguineous marriage is known to increase the prevalence of CP. ${ }^{14-16}$ In our study, it is found to be $34 \%$ which is more than the literature. ${ }^{8}$ The frequencies of comorbid pathologies were similar to the literature. ${ }^{8}$ Median birth time, weight and height were normal where the head holding, sitting, walking and speech times were delayed. The frequency of hypertension and diabetes during pregnancy was high which may lead to the prenatal risks for $\mathrm{CP}$.

Most common residential location of the $\mathrm{CP}$ patients was the rural areas similar to the literature. ${ }^{17}$ Most of the male CP patients were living in the city where the females were living in villages. Contrast to the previous reports ${ }^{18}$ the education level of the $\mathrm{CP}$ patients' parents in our study was very low. Furthermore, the education level of the CP patients was very low, too. Although it wasn't statistically significant the education level of the males was lower than the females $(p=0.289)$. In contrast to expectations, children of the educated and working parents were least literate. Any of the CP patients was working. $5 \%$ of the parents weren't living together.

Similar to the literature low family income was common in this study.$^{17} 25 \%$ of the families had too low monetary income, $58 \%$ low, $14 \%$ moderate and only $5 \%$ decent monetary income. The education level of the CP patients was higher in the families with decent monetary income. Most of the caregivers of CP patients were mothers. Only the $12 \%$ of the caregivers were taking psychological support that may due to not reaching to the medical support.

According to the CP type, physical function, physical role function, social functioning and general health perception sub parameter values were higher in the hemiplegic group. This finding may show that the hemiplegic patients are much independent. From the figures, it can be seen that the prevalence of $\mathrm{CP}$ was increased by the years in Giresun which is contrast to the literature. ${ }^{5}$

Consanguineous marriage is a common risk factor for $\mathrm{CP}^{5}$ Also, it is more frequent in males than females. ${ }^{17,19} \mathrm{We}$ found the similar findings in our study but there was no difference between CP types according to the gender or consanguineous marriage.

\section{Conclusion}

$\mathrm{CP}$ is a disorder which has variable features. For understanding these features more population-based analysis should be conducted. Findings may facilitate the management of this disorder.

\section{Acknowledgements}

None.

\section{Conflict of interest}

The authors declare no conflict of interest.

\section{References}

1. Byrne R, Noritz G, Maitre NL. Implementation of early diagnosis and intervention guidelines for cerebral palsy in a high-risk infant follow-up clinic. Pediatr Neurol. 2017;76:66-71.

2. Ritzmann R, Stark C, Krause A. Vibration therapy in patients with cerebral palsy: a systematic review. Neuropsychiatr Dis Treat. 2018;14:1607-1625.

3. Choi JY, Park J, Choi YS, et al. Functional communication profiles in children with cerebral palsy in relation to gross motor function and manual and intellectual ability. Yonsei Med J. 2018;59(5):677-685.

4. Forthun I, Strandberg LK, Wilcox AJ, et al. Parental socioeconomic status and risk of cerebral palsy in the child: evidence from two Nordic population-based cohorts. Int J Epidemiol .2018;47(4):1298-1306.

5. Aydın R. Epidemiology of Cerebral Palsy. Türkiye Klinikleri JPM\&RSpecial Topics. 2009;2(2):1-7.

6. Serdaroglu A, Cansu A, Ozkan S, et al. Prevalence of cerebral palsy in Turkish children between the ages of 2 and 16 years. Dev Med Child Neurol. 2006;48(6):413-416.

7. Surveillance of cerebral palsy in europe. surveillance of cerebral palsy in europe: a collaboration of cerebral palsy surveys and registers. surveillance of cerebral palsy in europe (SCPE). Dev Med Child Neurol. 2000;42(12):816-824. 
8. Cagliyan Turk A, Ozel S. Demographic and clinical features of patients with cerebral palsy that we followed. JPMR Sci. 2018;21(2):71-77.

9. Yalcinkaya EY, Huner B, Dincer U, et al. Demographic and clinical findings of cerebral palsy patients in Istanbul: a multicenter study. Turk $J$ Phys Med Rehab. 2014;60(1):134-138.

10. Fidan F, Baysal O. Epidemiologic characteristics of patients with cerebral palsy. Open Journal of Therapy and Rehabilitation. 2014;2(3):126-132.

11. Erkin G, Delialioglu SU, Ozel S et al. Risk factors and clinical profiles in Turkish children with cerebral palsy: analysis of 625 cases. Int J Rehabil Res. 2008;31(1):89-91.

12. Huner B, Ozguzel MH, Telli $\mathrm{H}$, et al. Polikliniğimize başvuran serebral palsi hastalarının demografik ve klinik özellikleri. Okmeydanı Tip Dergisi. 2011;27(1):28-32.

13. Sigurdardóttir S, Thórkelsson $\mathrm{T}$, Halldórsdóttir $\mathrm{M}$, et al. Trends in prevalence and characteristics of cerebral palsy among Icelandic children born 1990 to 2003. Dev Med Child Neurol. 2009;51(5):356-363.
14. Aydın G, Caner K, Demir SO. Etiologic, demographic and clinical features of 314 cases with cerebral palsy and the effects of these features to the outcomes of the rehabilitation. Fiziksel Tip. 2005;8:33-40.

15. Sinha G, Corry P, Subesinghe D, et al. Prevalence and type of cerebral palsy in a British ethnic community: the role of consanguinity. Dev Med Child Neurol. 1997;39(4):259-262.

16. Rajeh S, Bademosi O, Awada A, et al. Cerebral palsy in Saudi Arabia: a case-control study of risk factors. Dev Med Child Neurol. 1991;33(12):1048-1052.

17. Tseng SH, Lee JY, Chou YL, et al. Association between socioeconomic status and cerebral palsy. PLoS ONE. 2018;13(1): e0191724.

18. Hadeya MH, Amal HA. Parental oral health knowledge, attitude, practice and caries status of sudanese cerebral palsy children. Ped Health Res. $2017 ; 2: 2$.

19. Raina SK, Razdan S, Nanda R. Prevalence of cerebral palsy in children $<10$ years of age in r.s. pura town of jammu and kashmir. J Trop Pediatr. 2011;57(4):293-295. 